\title{
Synthesis, crystal structure, and valence states of $\mathrm{Mn}$-substituted $\mathrm{La}_{2} \mathrm{RuO}_{5}$
}

\author{
S. Riegg, ${ }^{1, *}$ F. J. Garcia-Garcia, ${ }^{2}$ A. Reller, ${ }^{3}$ A. Loidl, ${ }^{1}$ and S. G. Ebbinghaus ${ }^{4}$ \\ ${ }^{1}$ Experimental Physics V, Center for Electronic Correlations and Magnetism, University of Augsburg, D-86159 Augsburg, Germany \\ ${ }^{2}$ ICTS Centro Nacional de Microscopia Electronica, Universidad Complutense de Madrid, E-28040 Madrid, Spain \\ ${ }^{3}$ Resource Strategy, University of Augsburg, D-86159 Augsburg, Germany \\ ${ }^{4}$ Solid State Chemistry, Martin-Luther-University Halle-Wittenberg, D-06099 Halle, Germany \\ (Received 4 February 2014; revised manuscript received 13 June 2014; published 14 July 2014)
}

\begin{abstract}
Polycrystalline samples of layered perovskite-related $\mathrm{La}_{2} \mathrm{Ru}_{1-y} \mathrm{Mn}_{y} \mathrm{O}_{5}(0 \leqslant y \leqslant 0.25)$ were prepared by a soft-chemistry synthesis based on the thermal decomposition of a citrate precursor. The crystal structures of the compounds were determined by Rietveld analysis of x-ray diffraction patterns recorded at different temperatures. Additional neutron diffraction patterns for $\mathrm{La}_{2} \mathrm{Ru}_{0.75} \mathrm{Mn}_{0.25} \mathrm{O}_{5}$ were recorded between $1.5 \mathrm{~K}$ and $300 \mathrm{~K}$. A structural phase transition from a monoclinic room-temperature to a triclinic low-temperature phase was observed for $y \leqslant 0.20$, while for $y=0.25$ a phase separation at low temperatures was identified. The structural phase-transition temperatures decrease with increasing $\mathrm{Mn}$ concentration. Selected area electron diffraction of $\mathrm{La}_{2} \mathrm{Ru}_{0.75} \mathrm{Mn}_{0.25} \mathrm{O}_{5}$ documented the absence of cationic ordering of $\mathrm{Ru}$ and $\mathrm{Mn}$. The $\mathrm{Mn}$ and Ru oxidation states were determined using $\mathrm{x}$-ray absorption spectroscopy and showed a stable +4 valence for both elements in all samples investigated, at room temperature as well as at $110 \mathrm{~K}$.
\end{abstract}

DOI: 10.1103/PhysRevB.90.024406

PACS number(s): 61.05.C-, 61.05.F-, 61.50.Ks, 78.70.Dm

\section{INTRODUCTION}

A close relationship between structural transitions and changes of physical properties is found for many perovskiterelated transition-metal oxides. Even small variations of interatomic distances can generate, change, or suppress effects such as ferroelectricity, superconductivity, or magnetic ordering phenomena. In many cases the structural changes result from substitutions involving ions of different size or deviating valence. The structural relaxation during cooling can also lead to changes in the crystal structures and in turn tune new physical effects. These structure-property relationships can additionally be influenced by the replacement of metal cations by other elements with identical charge but different electronic configuration [1-5].

For the layered perovskite-related Ruddlesden-Popper (RP) phases $\left(A_{n+1} B_{n} \mathrm{O}_{3 n+1}\right)$ with mixed $\mathrm{Ru} / \mathrm{Mn}$ sites a rich variety of magnetic phases was reported. For the RP manganites it was shown that the physical properties are drastically influenced by the slab thickness $n$ [6]. One end member of the RP phases is the perovskite structure, which is defined by $n=\infty$. Substitution of $\mathrm{Ru}$ by $\mathrm{Mn}$ in $\mathrm{SrRu}_{1-x} \mathrm{Mn}_{x} \mathrm{O}_{3}$ causes a number of magnetic phases (ferromagnetic and antiferromagnetic orderings as well as spin and cluster glasses) depending on the manganese concentration $[7,8]$. Reducing the slab thickness to $n=2$ in $\mathrm{La}_{1.2} \mathrm{Sr}_{1.8} \mathrm{Mn}_{2-x} \mathrm{Ru}_{x} \mathrm{O}_{7}$ and $\mathrm{Sr}_{3} \mathrm{MnRuO}_{7}$ or to $n=1$ in $\mathrm{Sr}_{2} \mathrm{Mn}_{0.5} \mathrm{Ru}_{0.5} \mathrm{O}_{4}$ induces a variety of magnetic ordering phenomena emerging at different temperatures due to the competition of different magnetic exchange interactions [9-11]. In the Ru/Mn-based RP phases the complex magnetic ordering phenomena are caused by the mixing of $\mathrm{Ru}^{4+} / \mathrm{Ru}^{5+}$ and $\mathrm{Mn}^{3+} / \mathrm{Mn}^{4+}$ oxidation states and occurring charge ordering effects at lower temperatures. In addition, it was shown for $\mathrm{Sr}_{2} \mathrm{Ru}_{1-x} \mathrm{Mn}_{x} \mathrm{O}_{4}$ and $\mathrm{Sr}_{3}\left(\mathrm{Ru}_{1-x} \mathrm{Mn}_{x}\right)_{2} \mathrm{O}_{7}$ that structural effects such as changing bond lengths as well as the

*stefan.riegg@ physik.uni-augsburg.de distribution of the substituent play a significant role for the global and local magnetic effects in these systems [12-14].

The crystal structure of the perovskite-related oxides with the composition $\mathrm{La}_{2} \mathrm{Ru}_{1-y} \mathrm{Mn}_{y} \mathrm{O}_{5}$ described in this work has similarities but also significant differences compared with the RP oxides $\mathrm{Sr}_{2} \mathrm{Ru}_{1-y} \mathrm{Mn}_{y} \mathrm{O}_{4}$ [ $n=1$, Fig. 1(a)]. In both structure types monolayers of corner-sharing $(\mathrm{Ru} / \mathrm{Mn}) \mathrm{O}_{6}$ octahedra are separated by $A \mathrm{O}$ layers $(A=\mathrm{La}$ or $\mathrm{Sr})$ giving rise to a two-dimensional (2D) behavior. In the RP oxides the layers of metal-oxygen octahedra are planar. In contrast, for $\mathrm{La}_{2} \mathrm{Ru}_{1-y} \mathrm{Mn}_{y} \mathrm{O}_{5}$ as a modified member of the [110] phases [15], the metal-oxygen octahedra form zigzag layers with the composition $\mathrm{LaRu}_{1-y} \mathrm{Mn}_{y} \mathrm{O}_{4}$ [Fig. 1(b)], which alternate with $\mathrm{LaO}$ layers along the crystallographic $a$ axis [16-18]. These structural characteristics make a comparison of both substitution series highly interesting.

Unsubstituted $\mathrm{La}_{2} \mathrm{RuO}_{5}$ shows a simultaneous structural and magnetic phase transition accompanied by a small change of the electrical conductivity at $T_{d}=161 \mathrm{~K}[16,21]$. The paramagnetic high-temperature (ht) phase crystallizes in the monoclinic space group $\mathrm{P} 21 / \mathrm{c}$ (No. 14) and is semiconducting with a band gap of approximately $0.15 \mathrm{eV}$ as determined by electrical conductivity measurements [16]. In the lowtemperature (lt) phase the crystal structure is triclinic (space group P-1, No. 2) and the magnetic susceptibility decreases drastically to below $10^{-4} \mathrm{emu} / \mathrm{mol}$. In the temperature region $150 \leqslant T \leqslant 170 \mathrm{~K}$ the simultaneous presence of both phases is observed indicating a first-order phase transition [16,22]. The $1 t$ modification is also semiconducting with a slightly increased band gap of roughly $0.21 \mathrm{eV}$ [16]. The diminishing susceptibility can be described by a singlet-pairing of next neighboring $\mathrm{Ru}^{4+}$ spin moments $(S=1)$ in dimers of zero total moment driven by the structural changes at $T_{d}$. This scenario was derived from spin-polarized density-functional theory calculations and detailed analysis of the magnetic susceptibility and the specific heat [19,20,23-25].

Investigations on rare-earth substituted $\mathrm{La}_{2-x} L_{x} \mathrm{RuO}_{5}$ $(L n=\mathrm{Pr}, \mathrm{Nd}, \mathrm{Sm}, \mathrm{Gd}, \mathrm{Dy})$ revealed that the paramagnetic 
(a)

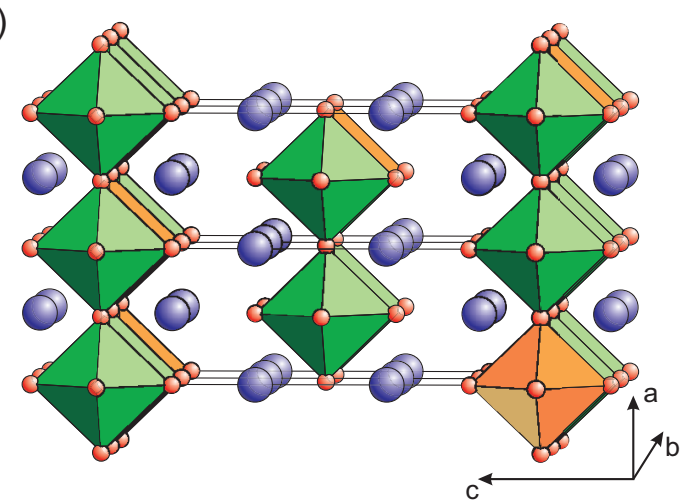

(b)

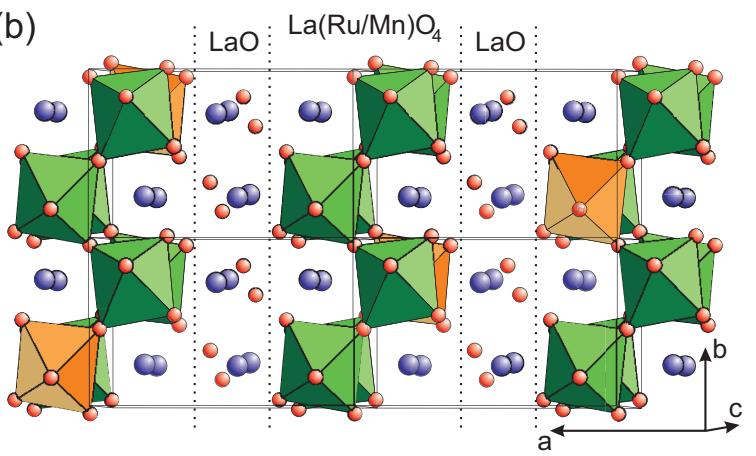

FIG. 1. (Color online) Crystal structures of $\mathrm{Sr}_{2} \mathrm{Ru}_{1-y} \mathrm{Mn}_{y} \mathrm{O}_{4}$ (a) and $\mathrm{La}_{2} \mathrm{Ru}_{1-y} \mathrm{Mn}_{y} \mathrm{O}_{5}$ (b). $\mathrm{La} / \mathrm{Sr}$ ions are represented by large blue spheres and oxygen by small red spheres. $\mathrm{RuO}_{6}$ octahedra are drawn in light green and the $\mathrm{Mn}$ substitution is represented by orange coloring. In (b) the alternating layering of $\mathrm{LaO}$ and $\mathrm{La}(\mathrm{Ru} / \mathrm{Mn}) \mathrm{O}_{4}$ along the $a$ axis is indicated by dotted lines.

$\mathrm{Ln}^{3+}$ ions, which are predominantly located in the $\mathrm{LaO}$ layers, do not significantly influence the magnetic phase transition $[20,22,26,27]$. Only a slight linear decrease of the dimerization temperature $T_{d}$ was observed in accordance with the decreasing unit-cell parameters, reflecting the smaller ionic radii of the $L n$ ions.

The substitution of Ru by $\mathrm{Ti}\left(\mathrm{La}_{2} \mathrm{Ru}_{1-y} \mathrm{Ti}_{y} \mathrm{O}_{5}\right)$ leads to a progressively decreasing $\mathrm{Ru}$-spin dimerization temperature, which becomes fully suppressed for $y=0.45$, the highest achievable substitution level [28]. The Ti incorporation directly interrupts the antiferromagnetic $\mathrm{Ru}-\mathrm{Ru}$ spin coupling. In turn, the decrease of $T_{d}$ linearly depends on the substitution level. The simultaneous replacement of $\mathrm{La}$ by $\mathrm{Pr}$ and $\mathrm{Ru}$ by $\mathrm{Ti}$ in $\mathrm{La}_{2-x} \mathrm{Pr}_{x} \mathrm{Ru}_{1-y} \mathrm{Ti}_{y} \mathrm{O}_{5}$ results in a completely additive behavior of the structural and magnetic properties for both rare-earth and Ti substitution [29].

In contrast to Ti substitution, incorporation of magnetic $\mathrm{Mn}$ ions in the Ru network is expected to create new interactions and new magnetic phases or ordering scenarios. To our best knowledge no isostructural manganite $\mathrm{La}_{2} \mathrm{MnO}_{5}$ has been reported to date and a complete substitution very probably cannot be achieved for the structural limitations described below.

The crystal structure of $\mathrm{La}_{2} \mathrm{Ru}_{1-y} \mathrm{Mn}_{y} \mathrm{O}_{5}$ was investigated by x-ray (XRD) and neutron powder diffraction (ND) at varying temperatures to study in detail the changes caused by $\mathrm{Mn}$ doping. In addition, phase transitions were recorded as a function of manganese concentration. Possible charge ordering of $\mathrm{Ru}^{4+} / \mathrm{Ru}^{5+}$ and $\mathrm{Mn}^{3+} / \mathrm{Mn}^{4+}$ was studied using $\mathrm{x}$-ray absorption spectroscopy.

\section{SYNTHESIS AND EXPERIMENTAL METHODS}

\section{A. Synthesis}

The polycrystalline samples of $\mathrm{La}_{2} \mathrm{Ru}_{1-y} \mathrm{Mn}_{y} \mathrm{O}_{5}$ could not be synthesized by solid-state reaction and were therefore prepared by a soft-chemistry method similar to the one described in Refs. [22] and [28]. A precursor solution was prepared by dissolving stoichiometric amounts of $\mathrm{La}\left(\mathrm{NO}_{3}\right)_{3} \times 6 \mathrm{H}_{2} \mathrm{O}$ (Chempur, 99.9\%), ruthenium nitrosyleacetate (Alfa Aesar, 99.99\%), $\mathrm{Mn}\left(\mathrm{NO}_{3}\right)_{2} \times 4 \mathrm{H}_{2} \mathrm{O}$ (Fluka, p.a.), and citric acid in roughly $50 \mathrm{ml}$ of deionized water. The weights of the starting agents were calculated to obtain final batches of $0.5 \mathrm{~g}$. For each mole of metal cation three moles of citric acid were added. The solutions were heated to $120{ }^{\circ} \mathrm{C}$ under stirring until gels formed. These gels were prereacted at $180{ }^{\circ} \mathrm{C}$ for two hours and then pyrolysed at $600^{\circ} \mathrm{C}$ for six hours in quartz crucibles. The obtained amorphous powders were well ground using agate mortar and pestle and calcined in air for at least 96 hours at $1175^{\circ} \mathrm{C}$ with intermediate grinding steps each 48 hours. For these calcination steps aluminium oxide crucibles were used. After each of the regrindings the phase purity was checked by x-ray powder diffraction.

\section{B. Experimental methods}

For structural analysis, XRD patterns were recorded at room temperature in the angular range $10^{\circ} \leqslant 2 \theta \leqslant 150^{\circ}$ using a Seifert 3003 TT $\theta-2 \theta$ powder diffractometer $(\mathrm{Cu}-$ $\mathrm{K}_{\alpha 1,2}$ radiation) equipped with a one-dimensional single-line semiconductor detector (METEOR-1D). A step width of $0.01^{\circ}$ and an integration time of $300 \mathrm{~s}$ per data point were chosen.

Additional XRD patterns were recorded at low $(100 \mathrm{~K})$ and room temperature using a STOE STADI $\mathrm{P}$ powder diffractometer with $\mathrm{Cu}-\mathrm{K}_{\alpha 1}$ radiation. The powders were mixed in a mass ratio of $1: 3$ with ground charcoal to dilute the strongly absorbing material and filled in capillaries with $0.3 \mathrm{~mm}$ diameter. A STOE IP-PDS detector was used and the temperature was controlled with a flowing-nitrogen cooling system (Oxford Cryosystems Cryostream 700). Diffraction patterns were recorded in the $2 \theta$ range $15^{\circ}$ to $130^{\circ}$. Ten patterns with an integration time of $600 \mathrm{~s}$ and a step width of $0.02^{\circ}$ were accumulated for the Rietveld analysis.

ND patterns of $\mathrm{La}_{2} \mathrm{Ru}_{0.75} \mathrm{Mn}_{0.25} \mathrm{O}_{5}$ were measured at the HRPT diffractometer of SINQ at the Paul Scherrer Institute, Switzerland [30]. The patterns were recorded at $300 \mathrm{~K}$, during the cooling process in steps of roughly $10 \mathrm{~K}$, and at $1.5 \mathrm{~K}$. A wavelength of $1.494 \AA$ (Ge 533 monochromator) and a step width of $0.05^{\circ}$ were chosen. The measured angular range was $8^{\circ} \leqslant 2 \theta \leqslant 164^{\circ}$.

High-resolution synchrotron XRD patterns were recorded between $10 \mathrm{~K}$ and room temperature at the beamline B2 at HASYLAB (DESY, Hamburg) [31]. The samples were mounted in $0.3 \mathrm{~mm}$ diameter capillaries and cooled with a closed-cycle helium cryostat. A wavelength of $0.56285 \AA(\approx 22 \mathrm{keV}$; Si-311 monochromator crystal) was used to measure the diffraction pattern in the angular range of $2^{\circ} \leqslant 2 \theta \leqslant 75^{\circ}$ with steps of 
$0.008^{\circ}$. The applied wavelength corresponds to an energy slightly lower than the Ru-K absorption edge, thus reducing the absorption. The patterns were recorded with the on-site readable position-sensitive image-plate detector (OBI; see Ref. [32]) with an integration time of roughly 15 minutes.

The Rietveld structure analysis was carried out with the FULLPROF program suite [33]. The refinement of the La- and Osite occupancies led to values close to unity and were therefore fixed in the final runs. Furthermore, the refinement of Ru and Mn occupation factors led to values very close to the nominal ones with a deviation of less than $1 \%$. The obtained crystal structure results are listed in the Supplemental Material [34].

Selected area electron diffraction (SAED) measurements were performed using a JEOL JEM-2100F transmission electron microscope.

XANES measurements were carried out in transmission mode at the beamline A1 at HASYLAB. For the measurements of the Mn-K absorption edge approximately $6 \mathrm{mg}$ of the samples were mixed with $20 \mathrm{mg}$ polyvinyl alcohol (PVA) and pressed into pellets of $13 \mathrm{~mm}$ diameter. The measurement for each sample was repeated four times and averaged to increase the signal-to-noise ratio. The absorption spectra of $\mathrm{MnO}, \mathrm{Mn}_{2} \mathrm{O}_{3}$, and $\mathrm{MnO}_{2}$ were recorded as a references for $\mathrm{Mn}^{2+}, \mathrm{Mn}^{3+}$, and $\mathrm{Mn}^{4+}$, respectively. For the investigation of the $\mathrm{Ru}-\mathrm{L}_{\mathrm{III}}$ absorption edge the samples were stuck to adhesive tape. Different ruthenium-oxides such as $\mathrm{RuO}_{2}$ and $\mathrm{La}_{2} \mathrm{RuO}_{5}$ were used as $\mathrm{Ru}^{4+}$ references. All spectra were energy calibrated using a $\mathrm{Mn}$ metal foil or $\mathrm{Ru}$ metal powder as references.

\section{CRYSTAL STRUCTURE AT ROOM TEMPERATURE}

Up to a substitution level of $y=0.25$ single-phase polycrystalline samples were obtained. Only traces (well below $1 \%$ ) of $\mathrm{LaRuO}_{3}$ or $\mathrm{La}_{3} \mathrm{RuO}_{7}$ were found for the higher substitution levels, perhaps due to minor deviations of the $\mathrm{Ru}$ content in the ruthenium nitrosyleacetate. For $y>0.25$ distinct amounts of $\mathrm{MnO}_{2}$ were detected indicating that 0.25 is the upper limit of $\mathrm{Mn}$ substitution in the $\mathrm{La}_{2} \mathrm{RuO}_{5}$ structure. This limit will be discussed below with respect to the different ionic radii of the $\mathrm{Ru}$ and $\mathrm{Mn}$ ions.

To investigate the possible existence of superstructures caused by cation ordering of $\mathrm{Ru}$ and $\mathrm{Mn}$ in more detail, SAED patterns were recorded. In Fig. 2 the zone axes [100], [010], and [001] of $\mathrm{La}_{2} \mathrm{Ru}_{0.75} \mathrm{Mn}_{0.25} \mathrm{O}_{5}$ are depicted. The absence of additional reflexes excludes the possible occurrence of $\mathrm{Ru} / \mathrm{Mn}$ ordering. The extinction rules derived from the patterns are the same as found for $\mathrm{La}_{2} \mathrm{RuO}_{5}$ (see Ref. [17]) and correspond to space group $\mathrm{P} 2{ }_{1} / \mathrm{c}$. The unit-cell parameters agree well with the values found by $\mathrm{x}$-ray and neutron powder diffraction.

The XRD patterns recorded at room temperature were analyzed by Rietveld refinements. The results show that $\mathrm{La}_{2} \mathrm{Ru}_{1-y} \mathrm{Mn}_{y} \mathrm{O}_{5}$ crystallizes in the monoclinic ( $\left.\mathrm{P} 2_{1} / \mathrm{c}\right)$ modification, isostructural to pure $\mathrm{La}_{2} \mathrm{RuO}_{5}$, in agreement with the SAED patterns. As an example for the fit quality, the refinement of $\mathrm{La}_{2} \mathrm{Ru}_{0.8} \mathrm{Mn}_{0.2} \mathrm{O}_{5}$ is depicted in Fig. 3. In the inset, the angular range $30.25^{\circ} \leqslant 2 \theta \leqslant 31.75^{\circ}$ is shown in detail for the $y$ values $0,0.05,0.1,0.15,0.2$, and 0.25 . The peaks at approximately $30.7^{\circ}$ correspond to the $h k l$ values (l 112 2) and (l $\left.\begin{array}{lll}0 & 2 & 0\end{array}\right)$ and show an increasing splitting with increasing $\mathrm{Mn}$ concentration $y$. This effect is caused by the decrease of cell parameter $b$, which shifts the (l) 20 ) peak to higher $2 \theta$ values.

Figure 4 shows the Rietveld refinement of the ND pattern of $\mathrm{La}_{2} \mathrm{Ru}_{0.75} \mathrm{Mn}_{0.25} \mathrm{O}_{5}$ recorded at $300 \mathrm{~K}$. The very good fit quality verifies that $\mathrm{La}_{2} \mathrm{Ru}_{1-y} \mathrm{Mn}_{y} \mathrm{O}_{5}$ crystallizes isostructural to pure $\mathrm{La}_{2} \mathrm{RuO}_{5}$. In addition, no peaks belonging to possible superstructures resulting from a cationic ordering were observed, which indicates a completely statistical occupation of $\mathrm{Mn}$ on the $\mathrm{Ru}$ sites. The refinement of the $\mathrm{Mn}$ occupancy yielded a value of $0.24(2)$, which is very close to the nominal concentration $y=0.25$. The $\mathrm{Mn} / \mathrm{Ru}$ occupation can be obtained with high reliability due to the strongly different scattering lengths of $\mathrm{Ru}(7.02 \mathrm{fm})$ and $\mathrm{Mn}(-3.75 \mathrm{fm})$, while their absorption cross sections are similar [35]. Further detailed results of the Rietveld fits are given in the Supplemental Material [34].

The cell parameters obtained from the Rietveld analysis of the XRD data are depicted in Figs. 5(a) and 5(b). The unit-cell axes are shown in the left frame [Fig. 5(a)], while the values of $\beta$ are displayed in the top right frame [Fig. 5(b)]. The $a$ axis as well as the cell parameter $b$ decrease linearly for increasing $y$; however, for $b$ the decrease is significantly larger. In contrast, the $c$ axis and the monoclinic angle $\beta$ are increasing linearly with increasing substitution level. The most significant changes of the axis lengths are found for the axes $b$ and $c$ due to the $\mathrm{Mn}$ incorporation within the $\mathrm{LaRuO}_{4}$ layers, which also induces the increase of $\beta$. On the other hand, the observed slight decrease of $a$ results from slightly shorter $\mathrm{Ru}-\mathrm{O}$ bond lengths in the $a b$ plane, which is discussed below in more detail.
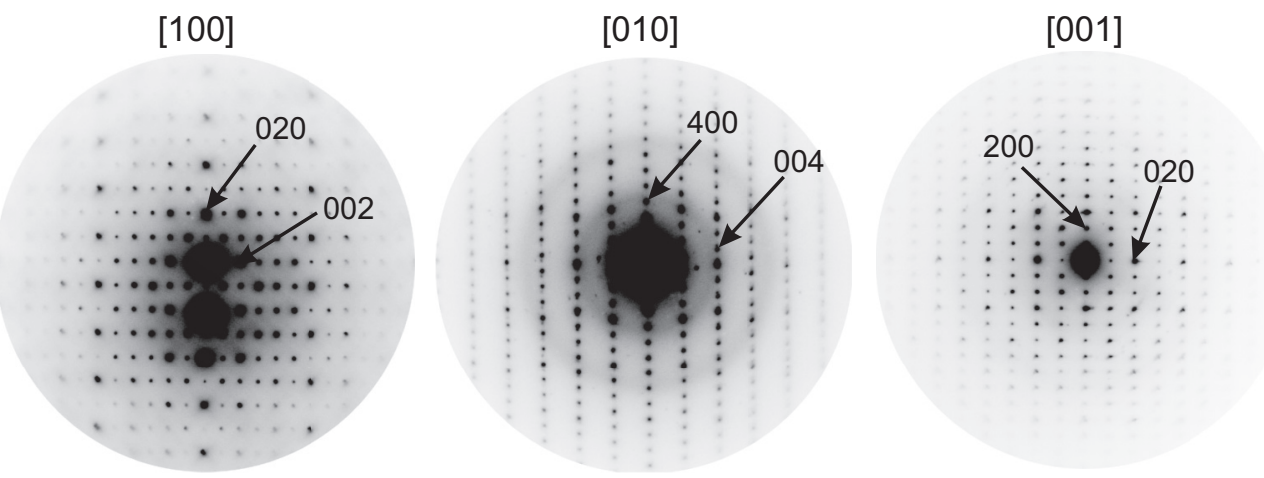

FIG. 2. SAED patterns observed for the zone axes [100], [010], and [001] of $\mathrm{La}_{2} \mathrm{Ru}_{0.75} \mathrm{Mn}_{0.25} \mathrm{O}_{5}$. 


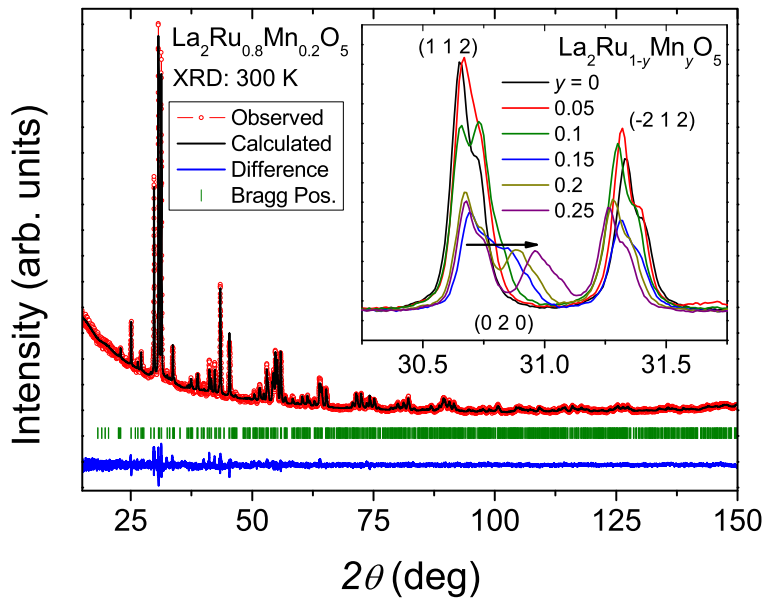

FIG. 3. (Color online) Rietveld refinement of the X-ray diffraction pattern of $\mathrm{La}_{2} \mathrm{Ru}_{0.8} \mathrm{Mn}_{0.2} \mathrm{O}_{5}$ measured with $\mathrm{Cu}-\mathrm{K}_{\alpha 1,2}$ radiation at room temperature. Inset: Details of the patterns for $y=0,0.05,0.1$, $0.15,0.2$, and 0.25 in the angular range between $30.25^{\circ}$ and $31.75^{\circ}$.

The relative changes of the unit-cell parameters are shown in Fig. 5(c). The values were obtained by normalizing the cell parameters of $\mathrm{La}_{2} \mathrm{Ru}_{1-y} \mathrm{Mn}_{y} \mathrm{O}_{5}$ to their corresponding value for unsubstituted $\mathrm{La}_{2} \mathrm{RuO}_{5}$. As discussed above, the parameters $b$ and $c$ show the strongest manganese concentration $y$ dependency with changes of roughly $\pm 1 \%$, while cell parameter $a$ only slightly decreases by $0.2 \%$. The rather small changes ranging below $1 \%$ indicate the minor effect of differences between the $\mathrm{Ru}$ and $\mathrm{Mn}$ ionic radii. The small decrease of the unit-cell volume by $0.5 \%$ mainly results from the slightly enlarged monoclinic angle $\beta$. The described changes are different to the unit-cell evolution in $\mathrm{La}_{2-x} L n_{x} \mathrm{RuO}_{5}$, where the volume decrease is mainly caused by a shortening of the $a$ axis. On the other hand, in $\mathrm{La}_{2} \mathrm{Ru}_{1-y} \mathrm{Ti}_{y} \mathrm{O}_{5}$ the volume reduction is determined by the decrease of the $b$ axis and the simultaneous increase of $\beta[22,28]$.

More detailed information on the structural changes caused by the Mn substitution was obtained from the Rietveld analysis of the ND data. The values for the ht phase of $\mathrm{La}_{2} \mathrm{RuO}_{5}$ were

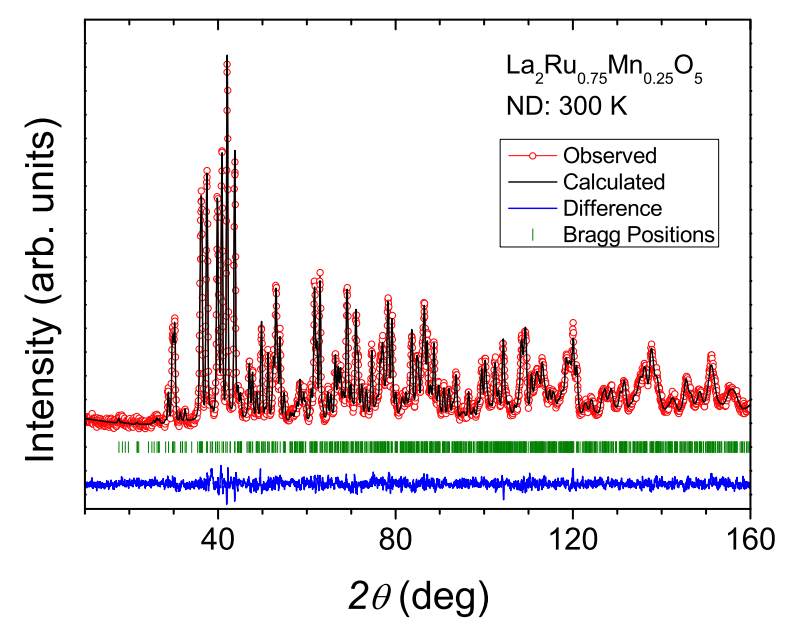

FIG. 4. (Color online) Rietveld refinement of the $\mathrm{La}_{2} \mathrm{Ru}_{0.75} \mathrm{Mn}_{0.25} \mathrm{O}_{5}$ neutron diffraction pattern measured at $300 \mathrm{~K}$ with $\lambda=1.494 \AA$.

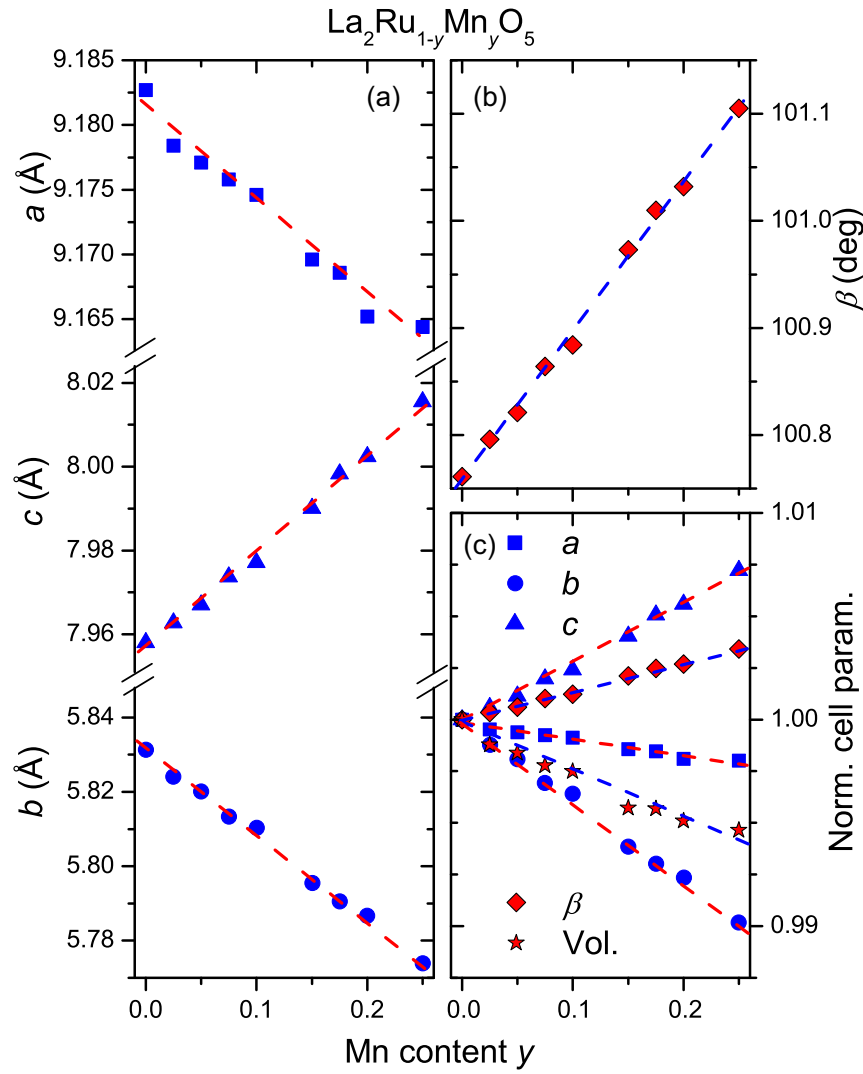

FIG. 5. (Color online) Cell parameters for $\mathrm{La}_{2} \mathrm{Ru}_{1-y} \mathrm{Mn}_{y} \mathrm{O}_{5}$ derived from Rietveld analysis of powder XRD data at room temperature. (a) Cell parameters $a, c$, and $b$. (b) Monoclinic angle $\beta$. Error bars are smaller than the size of the symbols. (c) Relative change of the unit-cell parameters. The cell parameters of $\mathrm{La}_{2} \mathrm{Ru}_{1-y} \mathrm{Mn}_{y} \mathrm{O}_{5}$ were normalized to their corresponding values of $\mathrm{La}_{2} \mathrm{RuO}_{5}$. All dashed lines are drawn to guide the eye.

taken from Ref. [18] and are compared to $\mathrm{La}_{2} \mathrm{Ru}_{0.75} \mathrm{Mn}_{0.25} \mathrm{O}_{5}$. The observed changes of the crystal structure are shown in Fig. 6. The notation of the oxygens (corresponding to the one used in Ref. [22]) is used to compare the Ru-O bond lengths and angles. The octahedra in $\mathrm{La}_{2} \mathrm{RuO}_{5}$ (transparent) and $\mathrm{La}_{2} \mathrm{Ru}_{0.75} \mathrm{Mn}_{0.25} \mathrm{O}_{5}$ (opaque) are shown projected along the $c$ axis and fixed on the same central oxygen ion (O5) to increase the comparability of structural deviations. The distorted square shaped $\mathrm{Ru}-\mathrm{O}$ coordination in the $a b$ plane is marked by the dashed $\left(\mathrm{La}_{2} \mathrm{RuO}_{5}\right)$ and solid blue $\left(\mathrm{La}_{2} \mathrm{Ru}_{0.75} \mathrm{Mn}_{0.25} \mathrm{O}_{5}\right)$ lines. It shows that the $a b$-plane coordination within the octahedra is changed very little. Nevertheless, it is obvious that the distance between top and bottom O5 atoms is shorter for the Mn-substituted sample reflecting the $b$-axis shortening. This is supported by the increase of the $\mathrm{Ru}-\mathrm{O} 5-\mathrm{Ru}$ angle by roughly $2^{\circ}$ from $155.4^{\circ}$ to $157.5^{\circ}$, as shown in Fig. 6 . The La atoms remain on almost identical positions in the rhombicshaped space between the rows of octahedra along the $c$ direction.

Furthermore, while the $\mathrm{O} 2-\mathrm{Ru}-\mathrm{O} 2$ angle remains constant at roughly $178.5^{\circ}$, the $\mathrm{Ru}-\mathrm{O} 2-\mathrm{Ru}$ angle increases slightly from $152.8^{\circ}(y=0)$ to $153.6^{\circ}(y=0.25)$. This explains the observed increase of the $c$ axis for $\mathrm{La}_{2} \mathrm{Ru}_{0.75} \mathrm{Mn}_{0.25} \mathrm{O}_{5}$ compared to pure $\mathrm{La}_{2} \mathrm{RuO}_{5}$. 


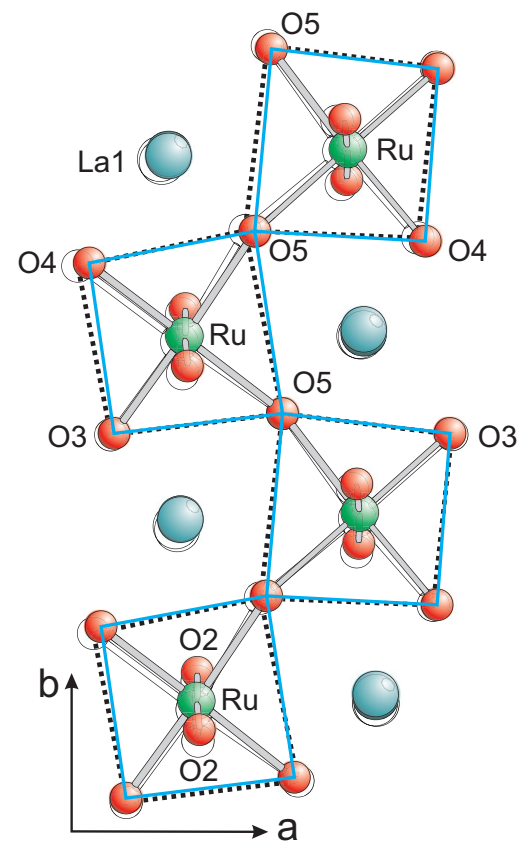

FIG. 6. (Color online) Ru-O coordination in the $\mathrm{LaRuO}_{4}$ layers projected along the $c$ axis for $\mathrm{La}_{2} \mathrm{RuO}_{5}$ (transparent) compared to $\mathrm{La}_{2} \mathrm{Ru}_{0.75} \mathrm{Mn}_{0.25} \mathrm{O}_{5}$ (opaque) as derived from ND data. The solid and dashed lines mark the $a b$ plane of the $\mathrm{RuO}_{6}$ octahedra.

The $(\mathrm{Ru} / \mathrm{Mn}) \mathrm{O}_{6}$ octahedra are depicted in Fig. 7 for $\mathrm{La}_{2} \mathrm{RuO}_{5}$ (left) and $\mathrm{La}_{2} \mathrm{Ru}_{0.75} \mathrm{Mn}_{0.25} \mathrm{O}_{5}$ (right). In order to simplify the discussion only the label $\mathrm{Ru}$ is used in the following for the mixed occupation of $\mathrm{Ru}$ and $\mathrm{Mn}$ on the $\mathrm{Ru}$ site. In the $a b$ plane, $\mathrm{O} 3$ and $\mathrm{O} 4$ are pointing towards the $\mathrm{LaO}$ layers while the two $\mathrm{O5}$ ions are connecting the corner-sharing octahedra in a zigzag arrangement. Parallel to the $c$ direction the octahedra are linked by the two $\mathrm{O} 2$ atoms. $\mathrm{The} \mathrm{Ru}-\mathrm{O}$ bond-length modifications are in agreement with the changes observed for the cell parameters $b$ and $c$. The $\mathrm{Ru}-\mathrm{O} 2$ distances increase according to $c$ and the $\mathrm{Ru}-\mathrm{O} 5$ distances decrease following the evolution of $b$. The obtained changes of $\mathrm{Ru}-\mathrm{O}$ bond lengths result in a stronger tetragonal distortion

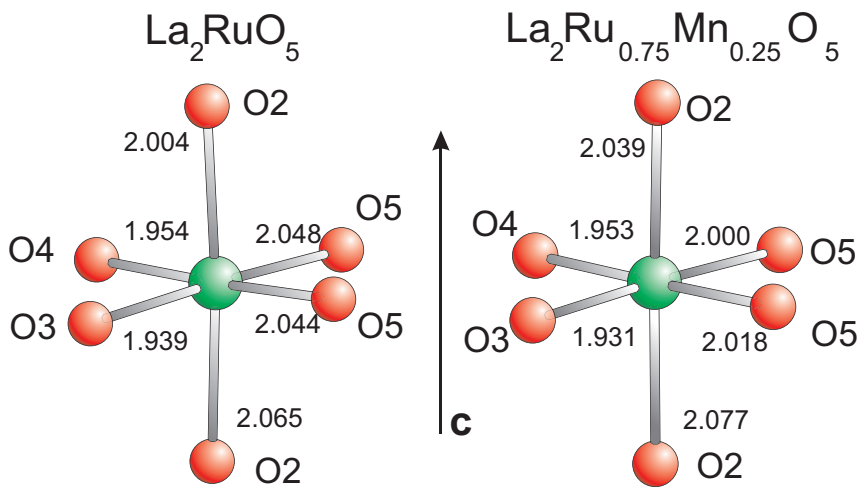

FIG. 7. (Color online) Comparison of the octahedral coordination of $\mathrm{Ru}$ in $\mathrm{La}_{2} \mathrm{RuO}_{5}$ (left) and $\mathrm{Ru} / \mathrm{Mn}$ in $\mathrm{La}_{2} \mathrm{Ru}_{0.75} \mathrm{Mn}_{0.25} \mathrm{O}_{5}$ (right). The oxygen atoms are labeled according to the tables in the Supplemental Material [34]. Bond lengths are given in $\AA$. of the octahedra for $\mathrm{La}_{2} \mathrm{Ru}_{0.75} \mathrm{Mn}_{0.25} \mathrm{O}_{5}$. This behavior would be expected for the Jahn-Teller active $\mathrm{Mn}^{3+}$ ions, but is not anticipated for $\mathrm{Mn}^{4+}$ with a $3 d^{3}$ configuration in octahedral coordination, which should favor a higher symmetry. In addition, the bond lengths for $\mathrm{Ru}-\mathrm{O} 3$ and $\mathrm{Ru}-\mathrm{O} 4$ also become slightly shortened in the range of several $\mathrm{m} \AA$.

The incorporation of $\mathrm{Mn}$ also affects the $\mathrm{Ru}-\mathrm{Ru}$ distances. For $y=0$ similar values of approximately $3.98 \AA$ for the $\mathrm{Ru}-$ Ru distance in the $c$ direction and $a b$ plane were reported [18]. For $y=0.25$ the $\mathrm{Ru}-\mathrm{Ru}$ distance parallel to $c$ is elongated to roughly $4.01 \AA$, while the one in the $a b$ plane is shortened to $3.94 \AA$. These values are close to the $\mathrm{Ru}-\mathrm{Ru}$ distances in the low-temperature phase of $\mathrm{La}_{2} \mathrm{RuO}_{5}(1.5 \mathrm{~K})$, where distances of $3.87 \AA / 3.92 \AA$ and $4.04 \AA / 4.05 \AA$ were observed. On the other hand, in the lt phase of $\mathrm{La}_{2} \mathrm{RuO}_{5}$ the bond lengths are alternating in the $b$ and $c$ directions (see, e.g., Ref. [19]), while in $\mathrm{La}_{2} \mathrm{Ru}_{0.75} \mathrm{Mn}_{0.25} \mathrm{O}_{5}$ no alternations occur due to the higher crystallographic symmetry. It has been argued that the alternating short and long $\mathrm{Ru}-\mathrm{Ru}$ distances are closely related to the magnetic dimerization phenomena in lt- $\mathrm{La}_{2} \mathrm{RuO}_{5}[16,19,25]$. Thus, the magnetic exchange interactions are expected to vary and probably cause a different magnetic phase transition for the Mn-substituted samples.

Bond valence sum (BVS) calculations [36] were performed for pure $\mathrm{La}_{2} \mathrm{RuO}_{5}$ (see Refs. [22,28]) and $\mathrm{La}_{2} \mathrm{Ru}_{0.75} \mathrm{Mn}_{0.25} \mathrm{O}_{5}$. The valences of the ions in the $\mathrm{LaO}$ layers amount to +3.2 for La and -2.4 for oxygen, which is comparable to the values reported for $\mathrm{La}_{2} \mathrm{RuO}_{5}[20,22,28]$ and is caused by smaller La sites than calculated from typical interatomic distances of $\mathrm{La}^{3+}$ and $\mathrm{O}^{2-}$. For the $\mathrm{LaRuO}_{4}$ layers the absolute values of the valences were slightly smaller than expected: The valences $\mathrm{Ru}+3.9, \mathrm{La}+2.9$, and $\mathrm{O}-1.9$ reflect the opposite effect of smaller anion and larger cation sites.

\section{LOW-TEMPERATURE CRYSTAL STRUCTURE}

As a consequence of the structural phase transition to the triclinic space group $\mathrm{P}-1$, changes of the interatomic distances and unit-cell parameters were observed for pure $\mathrm{La}_{2} \mathrm{RuO}_{5}[16,18]$. Due to bond length and angle variations, the magnetic exchange between the $\mathrm{Ru}$ ions is influenced and drives the singlet ground state with dimerized neighboring $\mathrm{Ru} S=1$ spins [16,19]. In the previous section the influence of the Mn substitution on the ht-phase structure was discussed. From the observed changes it can be expected that also the low-temperature crystal structure as well as the phase transition are significantly affected. The structural transition temperature, which is directly linked to the dimerization [22,28], decreases with increasing Mn substitution level. In the Supplemental Material details of the diffraction patterns of $\mathrm{La}_{2} \mathrm{Ru}_{0.85} \mathrm{Mn}_{0.15} \mathrm{O}_{5}$ and $\mathrm{La}_{2} \mathrm{Ru}_{0.80} \mathrm{Mn}_{0.20} \mathrm{O}_{5}$ are shown for different temperatures [34]. The structural transition temperature can be defined as the temperature at which a $50 \%-50 \%$ mixture of ht and lt phase occurs. Using this definition, transition temperatures of approximately $130 \mathrm{~K}$ for $y=0.15$ and $105 \mathrm{~K}$ for $y=0.20$ can be determined. For $\mathrm{La}_{2} \mathrm{Ru}_{0.75} \mathrm{Mn}_{0.25} \mathrm{O}_{5}$ a phase separation was observed as discussed below.

To study the effect of Mn substitution on the structural phase transition, the cell parameters at room temperature and $100 \mathrm{~K}$ 


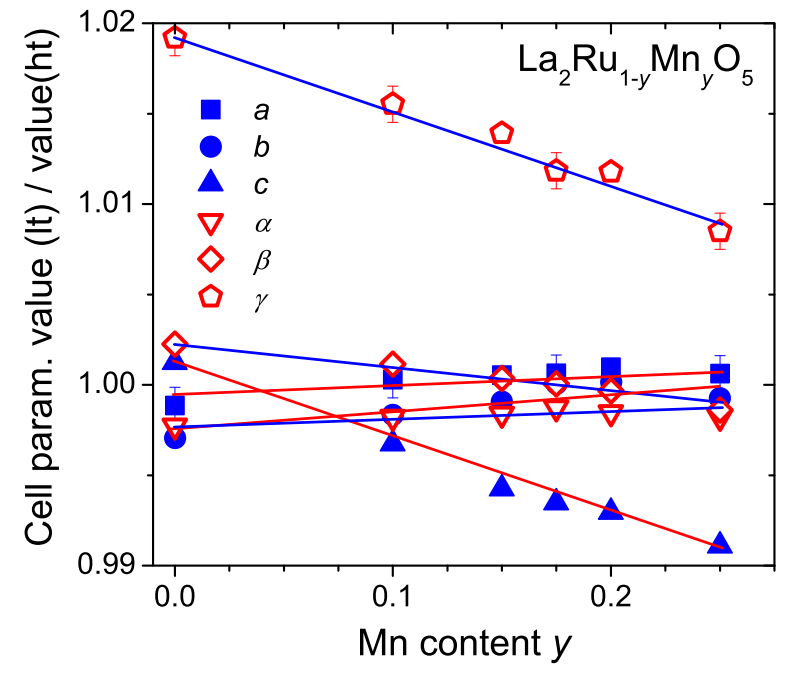

FIG. 8. (Color online) Comparison of the unit-cell parameters of the high-temperature $(300 \mathrm{~K})$ and the low-temperature $(100 \mathrm{~K})$ phase of $\mathrm{La}_{2} \mathrm{Ru}_{1-y} \mathrm{Mn}_{y} \mathrm{O}_{5}$. Values of $\alpha$ and $\gamma$ are $90^{\circ}$ in the ht phase.

were compared. In pure $\mathrm{La}_{2} \mathrm{RuO}_{5}$ the values for $a, b$, and $\alpha$ decrease during the transition from the ht to the lt modification, while $c, \beta$, and $\gamma$ increase. Except for $\gamma$, which decreases by $2 \%$ during the phase transition, all other parameters show small deviations of less than $0.3 \%$. In Fig. 8 the lt-cell parameters measured at $100 \mathrm{~K}$ normalized to the ht-phase values at $300 \mathrm{~K}$ are shown as a function of $y$. For $y=0,0.1$, and 0.175 the values were obtained from patterns recorded on a laboratory diffractometer (STOE STADI P), while for $y=0.15,0.2$, and 0.25 synchrotron-radiation diffraction was used. In the case of $a, b, \alpha$, and $\beta$ for concentrations $y \geqslant 0.15$ the values are close to unity for all samples, indicating that the phase transition barely affects these parameters. On the other hand, for $c$ and $\gamma$ a different behavior is observed. In the low-temperature phases, the values of $\gamma$ are reduced. With increasing Mn content the differences between ht and lt modifications become smaller; i.e., $\gamma_{\mathrm{lt}, 100 \mathrm{~K}} / \gamma_{\mathrm{ht}, 300 \mathrm{~K}}$ changes from 1.02 to 1.01 . For the $c$ axis the differences between ht and lt modifications increase with higher Mn contents from nearly 1.00 to 0.99 for $y=0.25$. It should be noted that although the observed changes seem to be rather small, they are clearly significant as indicated by the error bars shown in Fig. 8.

The structural changes between the ht and lt phase were determined in detail by Rietveld analysis of ND data for $\mathrm{La}_{2} \mathrm{Ru}_{0.75} \mathrm{Mn}_{0.25} \mathrm{O}_{5}$. In Fig. 9 the refinement result of the data recorded at $1.5 \mathrm{~K}$ is shown. A good agreement of measured data and Rietveld fit is achieved, but surprisingly a mixture of both the monoclinic ht and the triclinic lt modification is found at $1.5 \mathrm{~K}$. This is in contrast to the other Mn-substituted samples, where roughly $20 \mathrm{~K}$ below the transition temperature only the lt phase is present. For $\mathrm{La}_{2} \mathrm{Ru}_{0.75} \mathrm{Mn}_{0.25} \mathrm{O}_{5}$ a ratio of approximately $55 \% \mathrm{ht}$ and $45 \%$ lt modification was found at $1.5 \mathrm{~K}$. Very similar results were obtained from the synchrotron $\mathrm{x}$-ray diffraction data analysis. The same ratio of ht and $\mathrm{lt}$ phase was observed for the data recorded at $10 \mathrm{~K}$, which was the lowest temperature achievable in the synchrotron XRD measurements. In Fig. 10 the refinement results for $10 \mathrm{~K}$ (left) and $300 \mathrm{~K}$ (right) are depicted. While at room temperature

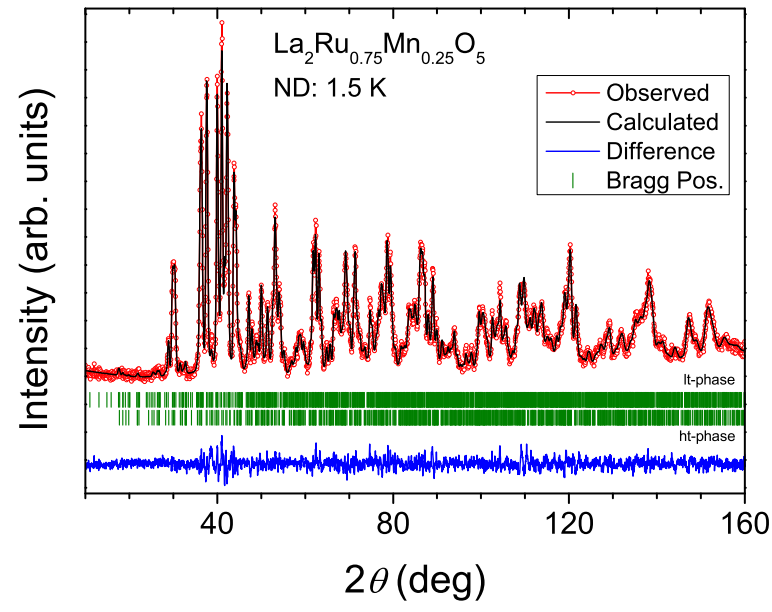

FIG. 9. (Color online) Rietveld refinement of the $\mathrm{La}_{2} \mathrm{Ru}_{0.75} \mathrm{Mn}_{0.25} \mathrm{O}_{5}$ neutron diffraction pattern measured at $1.5 \mathrm{~K}$ with $\lambda=1.494 \AA$ A. Bragg positions for both ht and lt phase are marked by green vertical dashes.

only the ht phase is present, at $10 \mathrm{~K}$ data a mixture of both modifications is observable by additional peaks which are characteristic for the lower symmetry of the triclinic unit cell. The fit quality for the low-temperature patterns is somewhat lower, as can be seen by the larger amplitude of the difference curve and in turn higher residual values. This result is not surprising taking into account the significantly increased number of fit parameters and strong correlations.

From the ND data $(1.5 \mathrm{~K})$ a Mn occupancy of $0.27(2)$ is obtained for the ht-phase and 0.20(2) for the lt-phase fraction. Weighed with their fractions $55 \%$ and $45 \%$, respectively, an average occupancy of $0.24(2)$ is achieved in excellent agreement with the nominal value of 0.25 and also with the room-temperature results. The fraction of $20 \% \mathrm{Mn}$ probably indicates an upper substitution limit, which allows the transformation to the lt modification and hence the dimerized

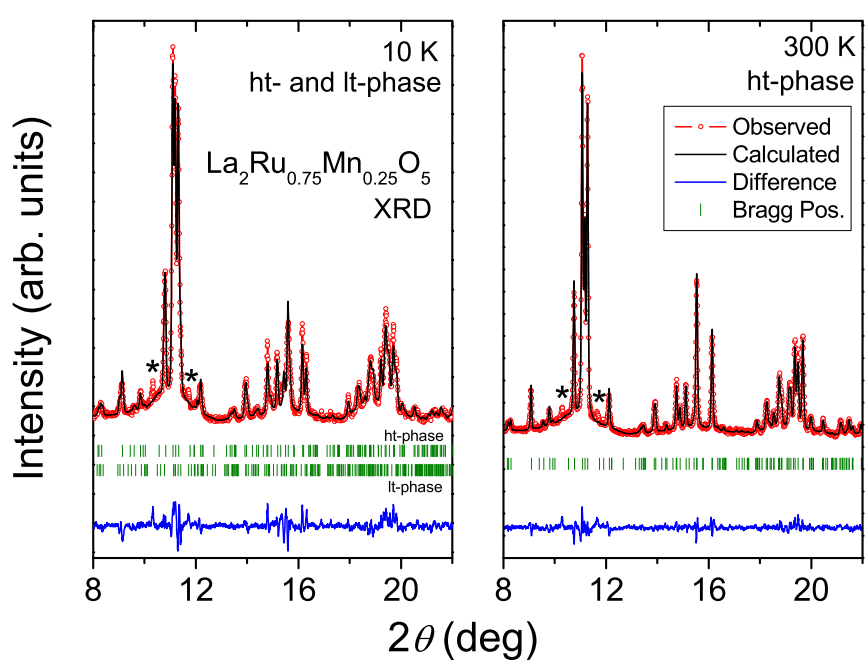

FIG. 10. (Color online) Rietveld refinement of the $\mathrm{La}_{2} \mathrm{Ru}_{0.75} \mathrm{Mn}_{0.25} \mathrm{O}_{5}$ x-ray diffraction pattern measured at $10 \mathrm{~K}$ (left) and $300 \mathrm{~K}$ (right) at the beamline B2 of HASYLAB with $\lambda=0.56285 \AA$. The asterisks mark traces of an impurity phase. 


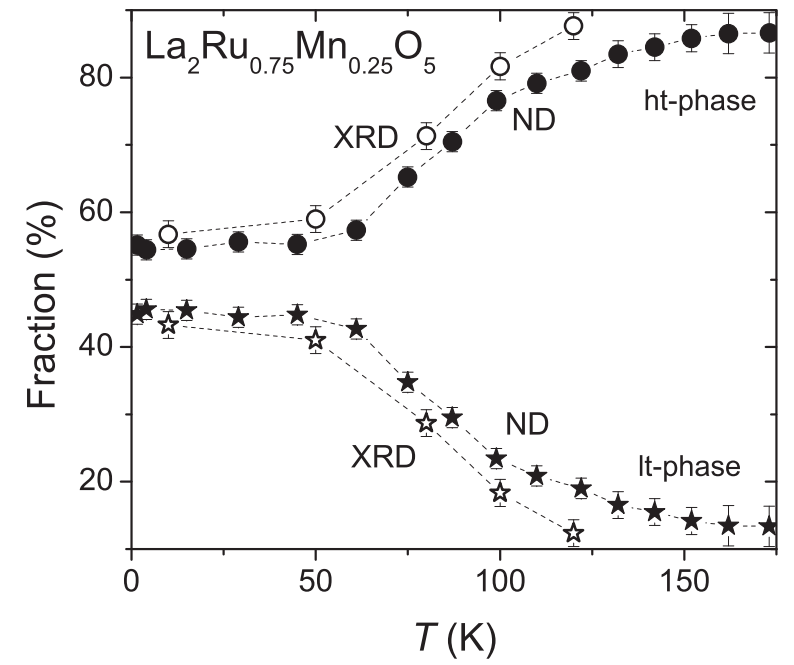

FIG. 11. Temperature dependence of the fraction of ht and lt modification in $\mathrm{La}_{2} \mathrm{Ru}_{0.75} \mathrm{Mn}_{0.25} \mathrm{O}_{5}$ from synchrotron-XRD and ND data.

ground state. But strikingly, at $300 \mathrm{~K}$ no remarkable splitting or broadening of the diffraction peaks can be observed in the ND and XRD pattern. Such a splitting would indicate the presence of two fractions with slightly varying Mn occupancy. Furthermore, the crystallites investigated with SAED showed neither additional reflexes nor a noticeable broadening and energy dispersive $\mathrm{x}$-ray spectroscopy did not yield varying $\mathrm{Mn}$ incorporation within the crystallites, either. This result is extraordinary, since for the lt phase for the samples with $y \leqslant$ 0.2 no deviation of the Mn content from the ht phase was found.

To study the temperature-dependent phase evolution, the relative fractions of the ht and lt phase for $\mathrm{La}_{2} \mathrm{Ru}_{0.75} \mathrm{Mn}_{0.25} \mathrm{O}_{5}$ are depicted in Fig. 11. The ND patterns were recorded during continuous cooling. In addition, synchrotron XRD patterns were analyzed. The values for both data sets are in good agreement and show smooth changes starting at $120 \mathrm{~K}$, which saturate below $50 \mathrm{~K}$ with a fraction of roughly $45 \%$ lt phase. At $150 \mathrm{~K}$ a fraction of approximately $11 \% \mathrm{lt}$ and $89 \% \mathrm{ht}$ phase was found in the ND patterns. In contrast, the XRD data document the absence of the lt modification above $130 \mathrm{~K}$. Due to the better signal-to-noise ratio of the XRD patterns it can be assumed that the fraction of lt phase in the ND patterns above $130 \mathrm{~K}$ is in fact significantly lower.

The incomplete phase transition for $\mathrm{La}_{2} \mathrm{Ru}_{0.75} \mathrm{Mn}_{0.25} \mathrm{O}_{5}$, which is apparently completed at $50 \mathrm{~K}$, is not easy to explain. An inhomogeneous distribution of the Mn ions comes to mind. On the other hand, such a chemical inhomogeneity should result in detectable splittings or at least broadening of the diffraction peaks (especially since the cell parameters were found to strongly change with $y$ ). Surprisingly we did not observe any such features even in the synchrotron data. This finding indicates that possible inhomogeneities can only exist on a very local scale. It is likely that due to the Mn incorporation the formation of $\mathrm{Ru}-\mathrm{Ru}$ spin dimers becomes locally suppressed as discussed in a subsequent article [37]. If the formation of such dimers is the driving force for the structural changes, it is reasonable that the transition remains incomplete.
TABLE I. Ru-O bond lengths and $\mathrm{Ru}-\mathrm{O}-\mathrm{Ru}$ bond angles in the ht and lt modification of $\mathrm{La}_{2} \mathrm{Ru}_{0.75} \mathrm{Mn}_{0.25} \mathrm{O}_{5}$ at $1.5 \mathrm{~K}$. ${ }^{\mathrm{a}}$ Errors amount to roughly $30 \mathrm{~m} \AA$ for the bond lengths and to $0.8^{\circ}$ for the bond angles.

\begin{tabular}{|c|c|c|c|}
\hline ht-phase & & lt-phase & \\
\hline Bond & $d(\AA)$ & Bond & $d(\AA)$ \\
\hline $\mathrm{Ru}-\mathrm{O} 2$ & 2.044 & $\mathrm{Ru}-\mathrm{O} 2$ & 2.024 \\
\hline $\mathrm{Ru}-\mathrm{O} 2$ & 2.075 & $\mathrm{Ru}-\mathrm{O} 2(\mathrm{a})$ & 2.164 \\
\hline $\mathrm{Ru}-\mathrm{O} 3$ & 1.915 & $\mathrm{Ru}-\mathrm{O} 3$ & 2.002 \\
\hline $\mathrm{Ru}-\mathrm{O} 4$ & 1.936 & $\mathrm{Ru}-\mathrm{O} 4(\mathrm{a})$ & 1.956 \\
\hline $\mathrm{Ru}-\mathrm{O} 5$ & 1.978 & $\mathrm{Ru}-\mathrm{O} 5$ & 2.003 \\
\hline \multirow[t]{7}{*}{$\mathrm{Ru}-\mathrm{O} 5$} & 2.003 & $\mathrm{Ru}-\mathrm{O} 5(\mathrm{a})$ & 1.884 \\
\hline & & $\mathrm{Ru}(\mathrm{a})-\mathrm{O} 2$ & 1.921 \\
\hline & & $\mathrm{Ru}(\mathrm{a})-\mathrm{O} 2(\mathrm{a})$ & 2.070 \\
\hline & & $\mathrm{Ru}(\mathrm{a})-\mathrm{O} 3(\mathrm{a})$ & 1.762 \\
\hline & & $\mathrm{Ru}(\mathrm{a})-\mathrm{O} 4$ & 1.854 \\
\hline & & $\mathrm{Ru}(\mathrm{a})-\mathrm{O} 5$ & 2.152 \\
\hline & & $\mathrm{Ru}(\mathrm{a})-\mathrm{O} 5(\mathrm{a})$ & 2.167 \\
\hline \multirow[t]{2}{*}{$\mathrm{Ru}-\mathrm{Ru}(a b)$} & 3.897 & $\mathrm{Ru}-\mathrm{Ru}(\mathrm{a})$ & $4.001(*)$ \\
\hline & & $\mathrm{Ru}-\mathrm{Ru}(\mathrm{a})$ & 4.060 \\
\hline \multirow[t]{2}{*}{$\mathrm{Ru}-\mathrm{Ru}(c)$} & 4.006 & $\mathrm{Ru}-\mathrm{Ru}(\mathrm{a})$ & $3.799(* *)$ \\
\hline & & $\mathrm{Ru}-\mathrm{Ru}(\mathrm{a})$ & 4.144 \\
\hline Angle & $\vartheta\left(^{\circ}\right)$ & Angle & $\vartheta\left({ }^{\circ}\right)$ \\
\hline \multirow[t]{2}{*}{$\mathrm{O} 2-\mathrm{Ru}-\mathrm{O} 2$} & 179.02 & $\mathrm{O} 2-\mathrm{Ru}-\mathrm{O} 2(\mathrm{a})$ & 175.83 \\
\hline & & $\mathrm{O} 2-\mathrm{Ru}(\mathrm{a})-\mathrm{O} 2(\mathrm{a})$ & 166.03 \\
\hline \multirow[t]{2}{*}{$\mathrm{O} 5-\mathrm{Ru}-\mathrm{O} 5$} & 96.86 & $\mathrm{O} 5-\mathrm{Ru}-\mathrm{O} 5(\mathrm{a})$ & 93.17 \\
\hline & & O5-Ru(a)-O5(a) & 91.58 \\
\hline \multirow[t]{2}{*}{$\mathrm{Ru}-\mathrm{O} 2-\mathrm{Ru}$} & 153.12 & $\mathrm{Ru}-\mathrm{O} 2-\mathrm{Ru}(\mathrm{a})$ & $148.78(* *)$ \\
\hline & & $\mathrm{Ru}-\mathrm{O} 2(\mathrm{a})-\mathrm{Ru}(\mathrm{a})$ & 156.45 \\
\hline \multirow[t]{2}{*}{$\mathrm{Ru}-\mathrm{O} 5-\mathrm{Ru}$} & 156.45 & $\mathrm{Ru}-\mathrm{O} 5-\mathrm{Ru}(\mathrm{a})$ & 155.47 \\
\hline & & $\mathrm{Ru}-\mathrm{O} 5(\mathrm{a})-\mathrm{Ru}(\mathrm{a})$ & $162.13(*)$ \\
\hline
\end{tabular}

${ }^{\text {a The oxygens } \mathrm{O} 3 \text { and } \mathrm{O} 4 \text { are pointing towards the } \mathrm{LaO} \text { layers. The }}$ $\mathrm{O} 2$ bridge the octahedra in the $c$ direction and the $\mathrm{O} 5$ connect them within the $a b$ plane.

The observed phase separation is rather unusual and, therefore, a detailed structural analysis was carried out using the neutron diffraction pattern of $\mathrm{La}_{2} \mathrm{Ru}_{0.75} \mathrm{Mn}_{0.25} \mathrm{O}_{5}$ measured at $1.5 \mathrm{~K}$ and $300 \mathrm{~K}$. This offers the opportunity to derive bond distances and angles for both modifications simultaneously at low temperatures and compare the values to the results of the room-temperature measurement. The values for the $\mathrm{Ru}-\mathrm{O}$ bond lengths, the $\mathrm{Ru}-\mathrm{Ru}$ distances, and the $\mathrm{O}-\mathrm{Ru}-\mathrm{O}$ and $\mathrm{Ru}-\mathrm{O}-\mathrm{Ru}$ bond angles of the $1.5 \mathrm{~K}$ measurement are listed in Table I. Details of the refinement results including cell parameters, residual values, atomic coordinates, and displacement parameters can be found in the Supplemental Material [34].

In the ht modification the $(\mathrm{Ru} / \mathrm{Mn}) \mathrm{O}_{6}$ octahedra document a typical thermal contraction from $300 \mathrm{~K}$ to $1.5 \mathrm{~K}$ characterized by slightly shortened $\mathrm{Ru}-\mathrm{O}$ bonds and almost constant angles. In the lt phase distinct deviations in the coordination of the emerging two $\mathrm{Ru}$ sites $[\mathrm{Ru}$ and $\mathrm{Ru}(\mathrm{a})]$ can be observed. Compared to the structural data of pure $\mathrm{La}_{2} \mathrm{RuO}_{5}$ the octahedral deformation caused by the symmetry reduction to the triclinic phase is in general more pronounced due to the Mn substitution. The $\mathrm{O} 2-\mathrm{Ru}-\mathrm{O} 2$ angle of $179.02^{\circ}$ indicates a small degree of deformation of the octahedra in the ht phase of $\mathrm{La}_{2} \mathrm{Ru}_{0.75} \mathrm{Mn}_{0.25} \mathrm{O}_{5}$. In the lt phase, on the other hand, the angle decreases to $175.83^{\circ}$ for $\mathrm{Ru}$ and even more drastically 
to $166.03^{\circ}$ for $\mathrm{Ru}(\mathrm{a})$ due to the pronounced off-center $\mathrm{Ru}$ site in this octahedron. In agreement with the off-center position of $\mathrm{Ru}$ the $\mathrm{Ru}-\mathrm{O}$ bond lengths in the $a b$ plane become systematically shorter for O3 and O4 by approximately $0.1 \AA$, while they are elongated by the same value for 05 . The smaller ionic radius of $\mathrm{Mn}^{4+}$ compared to $\mathrm{Ru}^{4+}$ allows for that larger displacement of the central ion in the octahedra.

With respect to the distinctly reduced O2- $\mathrm{Ru}(\mathrm{a})-\mathrm{O} 2$ angle the shortest $\mathrm{Ru}-\mathrm{Ru}$ distance is also found along $c$ (marked with $* *$ in Table I); however, this is not the superexchange path corresponding to the Ru singlet formation [19]. According to Anderson, Kanamori, and Goodenough [38-40] the superexchange interaction strength strongly depends on the metal-oxygen-metal bonding angles, which can be expressed by $J=J_{90} \sin ^{2} \vartheta+J_{180} \cos ^{2} \vartheta[41,42]$. In this equation $J_{90}$ is ascribed to the superexchange for $\vartheta=90^{\circ}$ and $J_{180}$ for $\vartheta=180^{\circ}$, respectively. According to Refs. [19] and [38] the ferromagnetic exchange $J_{90}$ is considered to be significantly smaller than the antiferromagnetic $J_{180}$. The corresponding angle $\vartheta$ for $\mathrm{Ru}-\mathrm{O} 2-\mathrm{Ru}$ for the shortest $\mathrm{Ru}-\mathrm{Ru}$ distance (**) is decreasing from $153.6^{\circ}$ at room temperature to $148.78^{\circ}$ at $1.5 \mathrm{~K}$, reflecting a strongly decreasing antiferromagnetic superexchange. In contrast, in the $a b$ plane one $\mathrm{Ru}-\mathrm{O} 5-$ $\mathrm{Ru}$ angle increases to $162.13^{\circ}$ (marked with $*$ in Table I) and additionally corresponds to the second shortest $\mathrm{Ru}-\mathrm{Ru}$ distance of $4.001 \AA$. Along this $\mathrm{Ru}-\mathrm{O} 5-\mathrm{Ru}$ path the singlet formation is very likely preferred due to the increasing antiferromagnetic superexchange similar to the results obtained for pure $\mathrm{La}_{2} \mathrm{RuO}_{5}$ [19]. This finding shows that the singlet formation depends more strongly on the $\mathrm{Ru}-\mathrm{O}-\mathrm{Ru}$ angle than on the $\mathrm{Ru}-\mathrm{O}$ distances, which do not change enough to explain the effect. By applying the superexchange description, the observed magnetic properties described in a following article can well be explained [37].

Based on the ND pattern, the temperature-dependent changes of the cell parameters were investigated for $\mathrm{La}_{2} \mathrm{Ru}_{0.75} \mathrm{Mn}_{0.25} \mathrm{O}_{5}$. Due to the incomplete phase transition the unit-cell parameters of the ht modification are available for the entire temperature range, i.e., from $300 \mathrm{~K}$ to $1.5 \mathrm{~K}$. The lt-phase data were available only for $T<120 \mathrm{~K}$. To improve comparability, the different parameters for ht and lt phase were normalized to the room-temperature values as depicted in Fig. 12. For the lt modification data for $\alpha$ and $\gamma$ are omitted because they remain very close to $90^{\circ}$. For the ht phase the thermal contraction of the unit cell by $0.5 \%$ is mainly a result of the shortening of the $a$ axis (i.e., along the alternating layering of the $\mathrm{LaO}$ and $\mathrm{LaRuO}_{4}$ layers). This preferred contraction is understandable since it is easier to change the interlayer distance than to stretch or compress layers of corner-sharing octahedra. The unit-cell volume decreases almost linearly between $300 \mathrm{~K}$ and $100 \mathrm{~K}$ with a slightly reduced slope down to $1.5 \mathrm{~K}$ (marked by the solid lines in Fig. 12). This is a typical behavior caused by the increasing rigidity of solids at low temperatures as already observed for $\mathrm{La}_{2} \mathrm{Ru}_{0.55} \mathrm{Ti}_{0.45} \mathrm{O}_{5}$ [28]. From the linear part above $80 \mathrm{~K}$ the thermal expansion was determined to $\alpha_{c}=20 \times 10^{-6} \mathrm{~K}^{-1}$, which is in the typical range for oxides. For the lt modification the increases/decreases of the corresponding cell parameters caused by the structural transition are visible. For both phases similar relative changes of the cell parameters are observed

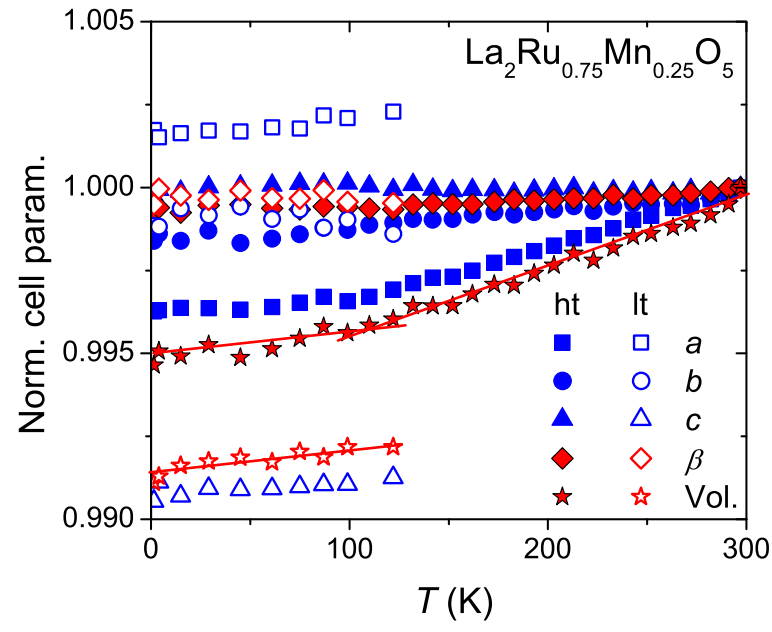

FIG. 12. (Color online) Relative change of the ht- (full symbols) and lt-phase (open symbols) unit-cell parameters of $\mathrm{La}_{2} \mathrm{Ru}_{0.75} \mathrm{Mn}_{0.25} \mathrm{O}_{5}$ from neutron diffraction pattern analysis. For better comparability the values at $T$ are normalized to their corresponding ht-modification values at $300 \mathrm{~K}$. Error bars are smaller than the size of the symbols.

with decreasing temperature. Below $100 \mathrm{~K}$ the slope of the lines indicates the volume change, which reduces to a thermal expansion factor of $\alpha_{c, \mathrm{lt}}=5 \times 10^{-6} \mathrm{~K}^{-1}$.

\section{VALENCE DETERMINATION USING XANES}

For an interpretation of the magnetic properties and structural changes the determination of the oxidation states of $\mathrm{Mn}$ and $\mathrm{Ru}$ in $\mathrm{La}_{2} \mathrm{Ru}_{1-y} \mathrm{Mn}_{y} \mathrm{O}_{5}$ is required since in oxides both elements can adopt different valence states (e.g., $\mathrm{Mn}^{2+}$, $\mathrm{Mn}^{3+}, \mathrm{Mn}^{4+}$ and $\mathrm{Ru}^{3+}, \mathrm{Ru}^{4+}, \mathrm{Ru}^{5+}$ ). This would allow charge ordering in $\mathrm{La}_{2} \mathrm{Ru}_{1-y} \mathrm{Mn}_{y} \mathrm{O}_{5}$. Very often mixed valences of $\mathrm{Mn}^{3+} / \mathrm{Mn}^{4+}$ and $\mathrm{Ru}^{4+} / \mathrm{Ru}^{5+}$ are found in $\mathrm{Mn}$-substituted ruthenates. Alternatively, both $\mathrm{Mn}$ and $\mathrm{Ru}$ ions could be tetravalent.

XANES measurements for selected $\mathrm{La}_{2} \mathrm{Ru}_{1-y} \mathrm{Mn}_{y} \mathrm{O}_{5}$ samples $(y=0.025,0.05,0.1,0.15,0.2,0.25)$ and reference oxides with known oxidation states and similar octahedral coordination were performed. In Fig. 13 the normalized absorption spectra at the Mn-K edge are shown in the left frame. The spectra of the reference oxides $\mathrm{MnO}\left(\mathrm{Mn}^{2+}\right), \mathrm{Mn}_{2} \mathrm{O}_{3}\left(\mathrm{Mn}^{3+}\right)$, and $\mathrm{MnO}_{2}\left(\mathrm{Mn}^{4+}\right)$ are depicted and dashed lines mark the corresponding edge energies which were determined from the first maxima of the derivatives of the spectra $[43,44]$. The measurements of the $\mathrm{La}_{2} \mathrm{Ru}_{1-y} \mathrm{Mn}_{y} \mathrm{O}_{5}$ samples were repeated four times and averaged to improve the signal-to-noise ratio. This averaging was necessary due to the low Mn content of some samples and the high absorption caused by the La- $\mathrm{L}_{\mathrm{I}}$ edge $(6266.3 \mathrm{eV})$ that is leading to a high background at the $\mathrm{Mn}-\mathrm{K}$ edge (6539.0 eV) [45]. Already at first sight the Mn-K spectra for all investigated Mn-substituted samples ( $y=$ $0.05,0.1,0.15,0.2,0.25)$ look very similar indicating similar valence states.

In the right frame of Fig. 13 the obtained edge energies for $\mathrm{La}_{2} \mathrm{Ru}_{1-y} \mathrm{Mn}_{y} \mathrm{O}_{5}$ are compared with the values of the reference compounds. The energy increases linearly with the 


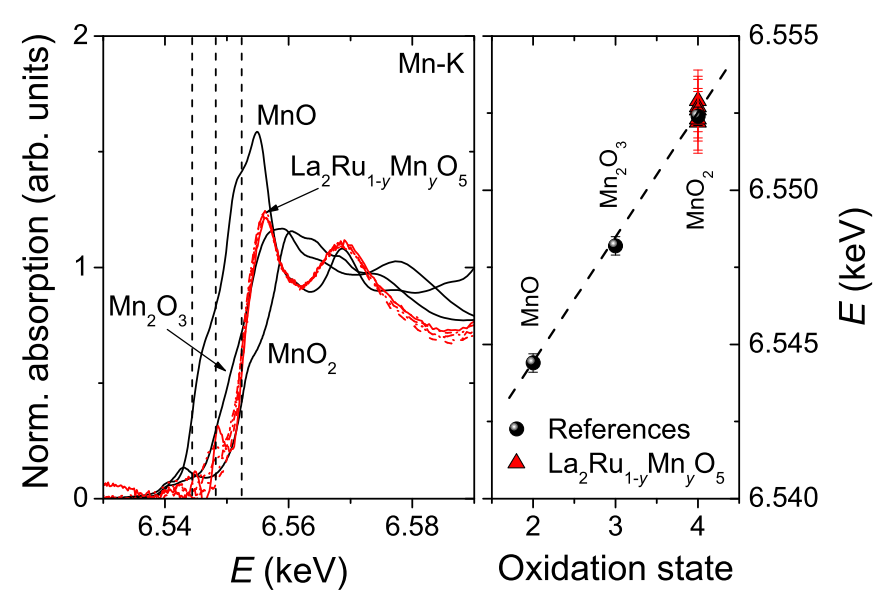

FIG. 13. (Color online) Left: Normalized Mn-K absorption spectra of reference manganese oxides and selected $\mathrm{La}_{2} \mathrm{Ru}_{1-y} \mathrm{Mn}_{y} \mathrm{O}_{5}$ samples $(y=0.05,0.1,0.15,0.2,0.25)$. The dashed lines mark the edge energy of the reference oxides reflecting the valencies $+2,+3$, and +4 . Right: $\mathrm{Mn}$ valence of the samples as determined from the first derivative of the Mn-K XANES.

Mn oxidation state and with a slope of roughly $4 \mathrm{eV}$ per oxidation number. The edge positions for $\mathrm{La}_{2} \mathrm{Ru}_{1-y} \mathrm{Mn}_{y} \mathrm{O}_{5}$ agree very well with the one of the $\mathrm{Mn}^{4+}$ reference. No significant difference in the spectra of the different $\mathrm{Mn}$ substitution levels could be found in detail. In conclusion, the $\mathrm{Mn}$ ions in $\mathrm{La}_{2} \mathrm{Ru}_{1-y} \mathrm{Mn}_{y} \mathrm{O}_{5}$ clearly have the oxidation state +4 .

For the $\mathrm{Ru}$ valence determination, $\mathrm{RuO}_{2}$ and unsubstituted $\mathrm{La}_{2} \mathrm{RuO}_{5}$ (from sol gel and solid-state synthesis) were used as reference materials, both possessing an oxidation number of +4 . The obtained edge energies are almost identical with previously reported data $[26,27,46-51]$. In the left frame of Fig. 14 the normalized spectra of the Ru- $\mathrm{L}_{\mathrm{III}}$ absorption edge are shown. The determination of the edge energy was performed by fitting the first derivative of the absorption edge with two pseudo-Voigt and one arctangent function [47] using the program WINXAS [52]. For the reference compounds the obtained energies of the maxima of the two pseudo-Voigt functions are marked by the dashed lines in the left frame of Fig. 14 (denoted as pV1 and pV2). The peak maxima of all spectra visibly exhibit very similar energies.

In the right frame of Fig. 14 the horizontal solid lines mark the peaks for the references. The obtained values are within experimental uncertainties in agreement with data reported in the literature $[22,47,48]$. The obtained energies for the $\mathrm{La}_{2} \mathrm{Ru}_{1-y} \mathrm{Mn}_{y} \mathrm{O}_{5}$ samples reveal a valence of +4 within experimental uncertainty of approximately $0.1 \mathrm{eV}$ as indicated by the dashed lines in Fig. 14. In addition, the energy spacing between the two pseudo-Voigt maxima is in good agreement with the value of 2.6(1) eV typically found for $\mathrm{Ru}^{4+}$ [47].

For $\mathrm{La}_{2} \mathrm{Ru}_{0.75} \mathrm{Mn}_{0.25} \mathrm{O}_{5}$ absorption spectra for both edges $\mathrm{Mn}-\mathrm{K}$ and $\mathrm{Ru}-\mathrm{L}_{\mathrm{III}}$ were also measured for temperatures down to $110 \mathrm{~K}$ which is significantly below the transition temperature. The spectra remain almost identical for all measured temperatures indicating constant valence and the absence of charge ordering, which could have been caused by the phase transition.

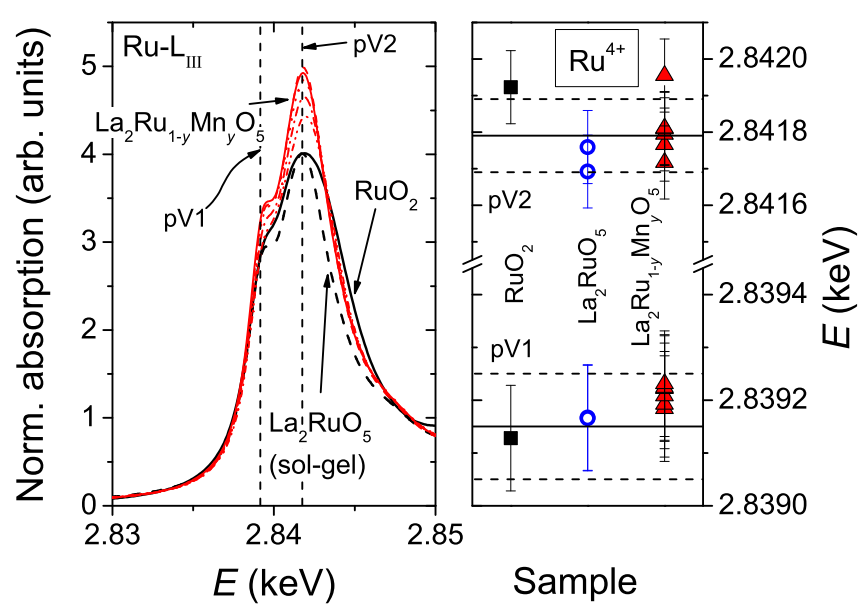

FIG. 14. (Color online) Left: Normalized Ru- $\mathrm{L}_{\text {III }}$ absorption spectra of reference oxides and selected $\mathrm{La}_{2} \mathrm{Ru}_{1-y} \mathrm{Mn}_{y} \mathrm{O}_{5}$ samples $(y=0.025,0.05,0.1,0.15,0.2,0.25)$. The dashed lines mark the positions of the two pseudo-Voigt fit maxima (pV1 and pV2). Right: $\mathrm{Ru}$ valence determined from the fit of the first derivative of the $\mathrm{Ru}-\mathrm{L}_{\mathrm{III}}$ XANES. The symbols represent the energies of the pseudo-Voigt peak-fit maxima. The horizontal solid lines indicate the $\mathrm{Ru}^{4+}$ energy determined from the references (see text).

As described for $\mathrm{La}_{2} \mathrm{Ru}_{1-y} \mathrm{Ti}_{y} \mathrm{O}_{5}$ and $\mathrm{La}_{2-x} \mathrm{Sr}_{x} \mathrm{Cu}_{1-y} \mathrm{Ru}_{y} \mathrm{O}_{4-\delta}$ [28,47], the full width at half maximum (FWHM) of the two pseudo-Voigt peaks utilized for the $\mathrm{Ru}-\mathrm{L}_{\mathrm{III}}$ fit can be used to estimate the distortion of the $\mathrm{RuO}_{6}$ octahedra. While the FWHM of pV1 (which can be assigned to a transition to empty orbitals of dominantly $t_{2 g}$ character) remains almost constant $(\approx 1.8 \mathrm{eV})$, the second pseudo-Voigt peak (transition to $e_{g}$-type orbitals) broadens with increasing Mn substitution level. The FWHM of the pseudo-Voigt peak pV2 is shown in Fig. 15, together with the ratios of the areas of $\mathrm{pV} 2 / \mathrm{pV} 1$. The FWHM of $\mathrm{pV} 2$ of pure $\mathrm{La}_{2} \mathrm{RuO}_{5}$ amounts to roughly $4.2 \mathrm{eV}$, which is significantly smaller than the approximately $6 \mathrm{eV}$ observed for $\mathrm{RuO}_{2}$ and $\mathrm{La}_{2-x} \mathrm{Sr}_{x} \mathrm{Cu}_{1-y} \mathrm{Ru}_{y} \mathrm{O}_{4-\delta}[28,47]$. With increasing $\mathrm{Mn}$ substitution level, the FWHM of $\mathrm{La}_{2} \mathrm{Ru}_{1-y} \mathrm{Mn}_{y} \mathrm{O}_{5}$ increases slightly up to $y=0.2$, while for $y=0.25$ a strong broadening is observed. As a result, the ratios of the peak areas $\mathrm{pV} 2 / \mathrm{pV} 1$ (Fig. 15) increase slowly between $0 \leqslant y \leqslant 0.2$ from

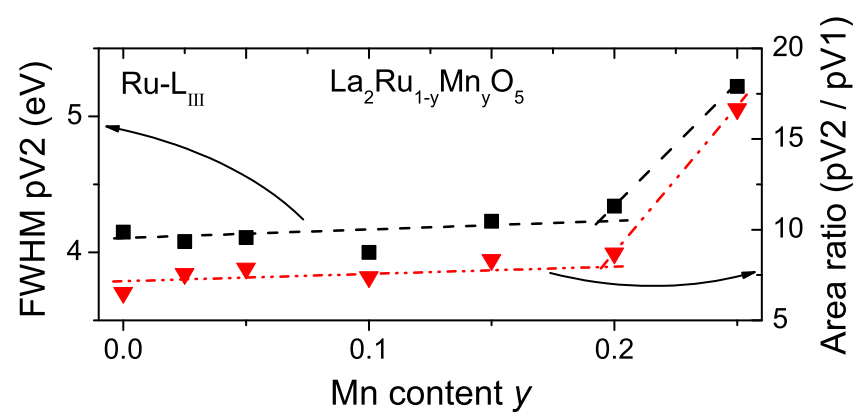

FIG. 15. (Color online) FWHM of the second pseudo-Voigt peak and area ratio of both peaks obtained from the fit of the normalized Ru- $\mathrm{L}_{\text {III }}$ absorption spectra. 
approximately 6.5 to 8.7 and then reveal a strong increase to 16.7 for $y=0.25$. This behavior reflects the strong distortion of the octahedra in $\mathrm{La}_{2} \mathrm{Ru}_{0.75} \mathrm{Mn}_{0.25} \mathrm{O}_{5}$. The $\mathrm{Ru}-\mathrm{O}$ bonds in the $c$ direction were found to be elongated compared to the very similar bond lengths within the $a b$ plane. This increasing quasitetragonal distortion can be explained taking into account the size of the $\mathrm{Mn}^{4+}$ ion $(0.53 \AA)$, which is too small for the $\mathrm{Ru}$ site $\left(\mathrm{Ru}^{4+}: 0.62 \AA\right)$ and therefore leads to a displacement similar to the situation found, e.g., in $\mathrm{BaTiO}_{3}$ [53].

In summary, the oxidation states of both $\mathrm{Mn}$ and $\mathrm{Ru}$ were determined to be +4 without charge ordering. This result is used for the interpretation of the magnetic properties discussed in detail in Ref. [37].

\section{SUMMARY AND CONCLUSION}

The partial substitution of $\mathrm{Ru}$ by $\mathrm{Mn}$ in $\mathrm{La}_{2} \mathrm{RuO}_{5}$ was successfully carried out applying a soft-chemistry reaction based on the thermic decomposition of citric acid stabilized precursors. The upper limit of the substitution level is reached at $y=0.25$. By XRD and ND it was found that the $\mathrm{La}_{2} \mathrm{Ru}_{1-y} \mathrm{Mn}_{y} \mathrm{O}_{5}$ samples crystallize in the same monoclinic structure as unsubstituted $\mathrm{La}_{2} \mathrm{RuO}_{5}$ without cationic ordering. Additional SAED data, which reveal no superstructure reflexes in the zone-axis patterns, support the assumption of a statistical distribution of $\mathrm{Mn}$ on the Ru site. The cell parameters $a$ and $b$ decrease with increasing substitution level, while $c$ and the monoclinic angle $\beta$ increase. The lattice constants and $\beta$ remain within the boundaries determined from $\mathrm{La}_{2-x} \mathrm{Ln}_{x} \mathrm{RuO}_{5}$ and $\mathrm{La}_{2} \mathrm{Ru}_{1-y} \mathrm{Ti}_{y} \mathrm{O}_{5}$ [22,28]. Due to the replacement of $\mathrm{Ru}^{4+}$ by smaller $\mathrm{Mn}^{4+}$ ions with $3 d^{3}$ configuration the local coordination in the $(\mathrm{Ru} / \mathrm{Mn}) \mathrm{O}_{6}$ octahedra changes significantly, resulting in a tetragonal elongation of the octahedra along $c$. Furthermore, the $\mathrm{Ru}-\mathrm{O}-\mathrm{Ru}$ bond angles change with $y$. Compared to pure $\mathrm{La}_{2} \mathrm{RuO}_{5}$, the angles along the $c$ axis increase by roughly $1^{\circ}$ while in the $a b$ plane a more significant increase of $2^{\circ}$ was found.

In rare-earth substituted samples $\left(\mathrm{La}_{2-x} L_{n} \mathrm{RuO}_{5}\right)$ the structural phase transition occurs independently of the rareearth element and substitution level [22]. For Ti substitution $\left(\mathrm{La}_{2} \mathrm{Ru}_{1-y} \mathrm{Ti}_{y} \mathrm{O}_{5}\right)$ the differences in lattice constants between the ht and lt phases decrease on increasing Ti concentration $y$ and vanish for $y=0.45$, where the structural transition becomes fully suppressed [28]. In the Mn-substituted samples, for $y \leqslant 0.2$ a structural transition into the triclinic lt phase was observed. Strikingly, $\mathrm{La}_{2} \mathrm{Ru}_{0.75} \mathrm{Mn}_{0.25} \mathrm{O}_{5}$ shows an incomplete transition; i.e., even at $1.5 \mathrm{~K}$ roughly $55 \%$ of the ht phase is still found in the Rietveld analysis of x-ray and neutron diffraction data. More interestingly, the apparently homogeneous ht modification separates at $120 \mathrm{~K}$ into an lt phase with lower Mn content and an ht phase with increased Mn substitution. This is rather astonishing considering that at room temperature no sign of two phases with deviating Mn concentrations was detected.

XANES measurements clearly reveal an oxidation state of +4 for both $\mathrm{Ru}$ and $\mathrm{Mn}$ ions. This result was rather unexpected since the larger $\mathrm{Mn}^{3+}$ better matches the size of $\mathrm{Ru}^{4+}$. In addition, no sign of a possible charge ordering was observed for $\mathrm{La}_{2} \mathrm{Ru}_{0.75} \mathrm{Mn}_{0.25} \mathrm{O}_{5}$ at $110 \mathrm{~K}$, i.e., well below the transition temperature. The observed structural deformations and BVS calculations, on the other hand, are in accordance with the finding of smaller tetravalent $\mathrm{Mn}$ ions.

The detailed results of the structural investigations as well as the observed valences provide important information for the interpretation of the interesting and unusual magnetic and thermodynamic properties. This is documented in a separate paper (Ref. [37]).

\section{ACKNOWLEDGMENTS}

The authors gratefully acknowledge the help of Dana Vieweg for low-temperature XRD measurements. This work is partly based on experiments performed at the Swiss spallation neutron source SINQ, Paul Scherrer Institute, Villigen, Switzerland. Technical assistance by Denis Sheptyakov is highly acknowledged. Thanks are due to the HASYLAB (DESY) for allocated beamtime and to Tony Bell (B2) and Edmund Welter (A1) for the helpful assistance. This work was supported by the Bavarian graduate school (Resource strategy concepts for sustainable energy systems) of the Institute of Materials Resource Management (MRM) of the University of Augsburg and partly by the DFG within the collaborative research unit TRR 80 (Augsburg, Munich, Stuttgart).
[1] M. Imada, A. Fujimori, and Y. Tokura, Rev. Mod. Phys. 70, 1039 (1998).

[2] A. S. Bhalla, R. Guo, and R. Roy, Mat. Res. Innovat. 4, 3 (2000).

[3] O. Auciello, Integrated Ferroelectrics 15, 211 (1997).

[4] Z. Fisk and J. L. Sarrao, Annu. Rev. Mater. Sci. 27, 35 (1997).

[5] E. Dagotto, T. Hotta, and A. Moreo, Phys. Rep. 344, 1 (2001).

[6] Y. Moritomo, A. Asamitsu, H. Kuwahara, and Y. Tokura, Nature (London) 380, 141 (1996).

[7] X.-Y. Zhang, Y. Chen, Z.-Y. Li, C. Vittoria, and V. G. Harris, J. Phys.: Condens. Matter 19, 266211 (2007).

[8] G. Cao, S. Chikara, X. N. Lin, E. Elhami, V. Durairaj, and P. Schlottmann, Phys. Rev. B 71, 035104 (2005).

[9] F. Weigand, S. Gold, A. Schmid, J. Geissler, E. Goering, K. Dörr, G. Krabbes, and K. Ruck, Appl. Phys. Lett. 81, 2035 (2002).
[10] B. Schüpp, K. Dörr, K. Ruck, K. Nenkov, K.-H. Müller, and G. Krabbes, Solid State Sci. 7, 17 (2005).

[11] D. J. Gallon, P. D. Battle, S. J. Blundell, J. C. Burley, A. I. Coldea, E. J. Cussen, M. J. Rosseinsky, and C. Steer, Chem. Mater. 14, 3976 (2002).

[12] J. E. Ortmann, J. Y. Liu, J. Hu, M. Zhu, J. Peng, M. Matsuda, X. Ke, and Z. Q. Mao, Sci. Rep. 3, 2950 (2013).

[13] B. Hu, G. T. McCandless, V. O. Garlea, S. Stadler, Y. Xiong, J. Y. Chan, E. W. Plummer, and R. Jin, Phys. Rev. B 84, 174411 (2011).

[14] G. Li, Q. Li, M. Pan, B. Hu, C. Chen, J. Teng, Z. Diao, J. Zhang, R. Jin, and E. W. Plummer, Sci. Rep. 3, 2882 (2013).

[15] F. Lichtenberg, A. Herrnberger, K. Wiedenmann, and J. Mannhart, Prog. Solid State Chem. 29, 1 (2001). 
[16] P. Khalifah, R. Osborn, Q. Huang, H. W. Zandbergen, R. Jin, Y. Liu, D. Mandrus, and R. J. Cava, Science 297, 2237 (2002).

[17] P. Boullay, D. Mercurio, A. Bencan, A. Meden, G. Drazic, and M. Kosec, J. Solid State Chem. 170, 294 (2003).

[18] S. G. Ebbinghaus, Acta Cryst. Sect. C 61, i96 (2005).

[19] S. Riegg, A. Günther, H.-A. Krug von Nidda, A. Loidl, M. V. Eremin, A. Reller, and S. G. Ebbinghaus, Phys. Rev. B 86, 115125 (2012).

[20] S. Riegg, A. Günther, H.-A. Krug von Nidda, M. V. Eremin, A. Reller, A. Loidl, and S. G. Ebbinghaus, Eur. Phys. J. B 85, 413 (2012).

[21] S. K. Malik, D. C. Kundaliya, and R. D. Kale, Solid State Commun. 135, 166 (2005).

[22] S. Riegg, U. Sazama, M. Fröba, A. Reller, and S. G. Ebbinghaus, Phys. Rev. B 84, 014403 (2011).

[23] V. Eyert, S. G. Ebbinghaus, and T. Kopp, Phys. Rev. Lett. 96, 256401 (2006).

[24] V. Eyert and S. G. Ebbinghaus, Prog. Solid State Chem. 35, 433 (2007).

[25] Hua Wu, Z. Hu, T. Burnus, J. D. Denlinger, P. G. Khalifah, D. G. Mandrus, L.-Y. Jang, H. H. Hsieh, A. Tanaka, K. S. Liang, J. W. Allen, R. J. Cava, D. I. Khomskii, and L. H. Tjeng, Phys. Rev. Lett. 96, 256402 (2006).

[26] S. G. Ebbinghaus, S. Riegg, T. Götzfried, and A. Reller, Eur. Phys. J. ST 180, 91 (2010).

[27] S. Riegg, A. Reller, and S. G. Ebbinghaus, J. Solid State Chem. 188, 17 (2012).

[28] S. Riegg, S. Widmann, A. Günther, H.-A. Krug von Nidda, A. Reller, A. Loidl, and S. G. Ebbinghaus, J. Phys.: Condens. Matter 25, 126002 (2013).

[29] S. Riegg, A. Loidl, A. Reller, and S. G. Ebbinghaus, Mater. Res. Bull. 48, 4583 (2013).

[30] P. Fischer, G. Frey, M. Koch, M. Könnecke, V. Pomjakushin, J. Schefer, R. Thut, N. Schlumpf, R. Bürge, U. Greuter, S. Bondt, and E. Berruyer, Physica B 276-278, 146 (2000).

[31] M. Knapp, C. Baehtz, H. Ehrenberg, and H. Fuess, J. Synchrotron Rad. 11, 328 (2004).
[32] M. Knapp, V. Joco, C. Baehtz, H. H. Brecht, A. Berghaeuser, H. Ehrenberg, H. von Seggern, and H. Fuess, Nucl. Instrum. Methods Phys. Res., Sect. A 521, 565 (2004).

[33] J. Rodriguez-Carvajal, Physica B 192, 55 (1993).

[34] See Supplemental Material at http://link.aps.org/supplemental/ 10.1103/PhysRevB.90.024406 for the detailed crystal-structure data.

[35] V. F. Sears, Neutron News 3, 26 (1992).

[36] I. D. Brown and D. Altermatt, Acta Crystallogr. Sect. B 41, 244 (1985).

[37] S. Riegg, A. Wintermeier, H.-A. Krug von Nidda, S. Widmann, A. Günther, A. Reller, S. G. Ebbinghaus, and A. Loidl, Phys. Rev. B 90, 024407 (2014).

[38] P. W. Anderson, Phys. Rev. 115, 2 (1959).

[39] J. Kanamori, J. Phys. Chem. Solids 10, 87 (1959).

[40] J. B. Goodenough, Magnetism and the Chemical Bond (Interscience Publishers, New York, 1963).

[41] K. Motida and S. Miyahara, J. Phys. Soc. Jpn. 28, 1188 (1970).

[42] M. V. Eremin, Fiz. Tverd. Tela (Sov. Phys. Solid State) 18, 2088 (1976).

[43] J. Garcia, G. Subias, V. Cuartero, and J. Herrero-Martin, J. Synchrotron Rad. 17, 386 (2010).

[44] F. Bridges, C. H. Booth, M. Anderson, G. H. Kwei, J. J. Neumeier, J. Snyder, J. Mitchell, J. S. Gardner, and E. Brosha, Phys. Rev. B 63, 214405 (2001).

[45] J. A. Bearden and A. F. Burr, Rev. Mod. Phys. 39, 125 (1967).

[46] I. Arcon, A. Bencan, A. Kodre, and M. Kosec, X-Ray Spectrom. 36, 301 (2007).

[47] S. G. Ebbinghaus, Z. Hu, and A. Reller, J. Solid State Chem. 156, 194 (2001).

[48] S. G. Ebbinghaus, J. Solid State Chem. 177, 817 (2004).

[49] T. Götzfried, A. Reller, and S. G. Ebbinghaus, Inorg. Chem. 44, 6550 (2005).

[50] M. H. Aguirre, D. Logvinovich, L. Bocher, R. Robert, S. G. Ebbinghaus, and A. Weidenkaff, Acta Mater. 57, 108 (2009).

[51] T. Götzfried, Ph.D. thesis, University of Augsburg, 2007.

[52] T. Ressler, J. Phys. IV (France) 7, 269 (1997).

[53] R. D. Shannon, Acta Crystallogr. Sect. A 32, 751 (1976). 